\title{
A Device for Ultraviolet Light Sanitization of Face Masks
}

\author{
Marilyn G Pray Grant and Patrick A Grant* \\ Department of Biomedical Science, Charles E. Schmidt College of Medicine, Florida Atlantic University, USA
}

*Corresponding author: Patrick A Grant, Department of Biomedical Science, Charles E. Schmidt College of Medicine,

Florida Atlantic University, Boca Raton, USA

\section{ARTICLE INFO}

Received: 㓞 June 16, 2021

Published: 豐 June 25, 2021

Citation: Marilyn G Pray Grant, Patrick A Grant. A Device for Ultraviolet Light Sanitization of Face Masks. Biomed J Sci \& Tech Res 36(5)-2021. BJSTR. MS.ID.005908.

Keywords: UVC Light; 254nm; COVID-19; Face Masks; Bacteria; Microorganisms; Sanitization

\begin{abstract}
Following the rapid emergence of the highly transmissible SARS-CoV-2 virus responsible for the COVID-19 disease face masks have become widely used to mitigate airborne spread of the virus from respiratory droplets and aerosols. UVC light has been demonstrated to effectively inactivate the SARS-CoV-2 virus and other microorganisms. Here we describe the use of an effective prototype device for the UVC sanitization of face masks or other personal items. Furthermore, we find that after each wear, microorganisms from even a healthy wearer's own respiratory droplets and skin can collect on the inside of the mask and these can similarly be sanitized using this device.
\end{abstract}

Abbreviations: CDC: Centers for Disease Control; WHO: World Health Organization; UVC: Ultraviolet C; SARS-CoV: Severe Acute Respiratory Syndrome Coronavirus; MERSCoV: Middle East Respiratory Syndrome Coronavirus; CFUs: Colony Forming Units

\section{Introduction}

The COVID-19 disease is caused by the severe acute respiratory syndrome coronavirus 2 (SARS-CoV-2), a novel beta-coronavirus that is primarily transmitted via respiratory droplets and aerosols with a likely more limited transmission risk via fomites [1-3]. After the first reports of the disease in December 2019, 120 million infections and 2.5 million deaths were reported worldwide by the World Health Organization (WHO) during the first year of the pandemic [1]. The use of face coverings to mitigate the spread of the virus became widespread after the US Centers for Disease Control (CDC) recommended their use in April of 2020, with a similar recommendation by the WHO and most health groups and other countries [4-7]. Leung et al. reported that face masks or coverings may prevent the spread of SARS-CoV-2 via trapping exhaled respiratory droplets [3]. Initially during the pandemic mask availability was limited and the use of N95 respirators and surgical masks was prioritized for health care facilities and the most vulnerable individuals. The increased production of cloth and surgical masks has helped with a wider availability of face coverings to the general population, however disposable masks are also anticipated to cause an environmental threat, including the eventual release of plastic particles from surgical masks and other personal protective equipment $[8,9]$.

A recent study estimated that 129 billion face masks are being used globally every month and most are disposable face masks [8]. The emergence of the recent vaccines for COVID-19 has led the CDC to change its recommendation on mask use for the fully vaccinated, while those who are not fully vaccinated are to follow the previous guidelines [10]. Thus mask use is likely to continue as long as SARS-CoV-2 infections persist and in the event of any future emergent pandemic. While cloth masks can routinely be reused after washing, it is recommended that the reuse of N95 and other types of disposable surgical masks should be avoided. However, it is suggested that in reality these masks are frequently reused, particularly during the dire mask shortage at the beginning of the pandemic or as individuals try to reduce their mask consumption $[11,12]$. In practical terms, a replacement for soiled 
masks may also not be immediately or conveniently available at all times. Furthermore, reducing mask waste will ultimately limit environmental impacts [9].

While masks are considered effective in limiting the transmission of COVID-19, we predicted that mask wearing would likely lead to the accumulation of both environmental and host microorganisms on internal and external mask surfaces. Of note, short wavelength Ultraviolet C (UVC) light at $254 \mathrm{~nm}$ has been implemented in hospitals to decontaminate N95 respirators, allowing their reuse and helping to preserve the supply of personal protective equipment $[13,14]$. UVC has been found to be effective at killing multiple coronaviruses, including Severe Acute Respiratory Syndrome Coronavirus (SARS-CoV), SARS-CoV-2, and Middle East Respiratory Syndrome Coronavirus (MERS-CoV) and has been used routinely for various medical and domestic microbial sterilization procedures [15-22]. Here we describe the development and use of a small portable device for the simultaneous UVC sanitization of multiple face masks or other small items. As proof of principle we tested the efficiency of the device for the killing of E.coli droplets on the inside of surgical masks and naturally occurring microorganisms recovered from donated worn masks.

\section{Methods and Materials}

A prototype self-contained UVC sanitization device was developed consisting of a central monochromatic UVC lamp with a surrounding hanging rack to hold multiple masks or other objects [23]. The technology operates at a UVC wavelength of approximately $254 \mathrm{~nm}$, which has the ability to kill bacteria, viruses, yeast, and mold spores. The device contains an outer casing to protect the users from the potentially damaging effects of UVC exposure. XL-1 Blue E.coli (Stratagene) were inoculated in Lysogeny Broth (LB) and grown overnight at $37 \mathrm{C}$ in a shaking incubator and then diluted 1:500 in LB. Multiple droplets of $5 \mathrm{ul}$ of E.coli were spotted approximately $1 \mathrm{~cm}$ apart across the inside surface (face-side) of surgical facemasks and incubated for 10 minutes at room temperature. The masks were then hung in the device and the inside surfaces were exposed to UVC light at a measured density of $0.8 \mathrm{~mW} / \mathrm{cm}^{2}$ at a distance of $10 \mathrm{~cm}$ from the light source for 0 (control), 30, 60 or 120 seconds. A sterile swab was used to recover surviving bacteria and streaked across the surface of LB plates and allowed to air dry. The plates were incubated overnight at $37 \mathrm{C}$ and colonies were counted after 24 hours to calculate time kill curves from samples in quintuplicate and the point of a $3 \log 10$-fold decrease in Colony Forming Units (CFUs), which represents $99.9 \%$ sanitization. Pairwise t-tests assuming equal variances were performed between untreated controls and that of each time point to calculate p-values. To assess sanitization of environmental microorganisms on face masks, we obtained cloth or surgical masks that had been worn for at least one day. The inside surface of the mask was swabbed prior to UVC exposure or after 5 minutes of UVC treatment, as described above. The swab was streaked across the surface of LB plates, grown for 24 hours at $37 \mathrm{C}$, and then photographed. Similarly a swab was taken from the glass touch screen of a mobile phone prior to UVC exposure or after 5 minutes of UVC treatment.

\section{Results}

To test the efficiency of UVC light in the sanitization of face masks a small self-contained and portable device was developed, capable of simultaneously hanging multiple masks or other personal items such as keys or cell phones [23]. E.coli were purposely spotted in droplets on the inner mask surface and then exposed to UVC irradiation for various times and surviving bacteria were recovered and grown on LB plates (Figure 1A). CFUs were counted and compared to untreated controls. We found that UVC treatment of masks for 30 seconds led to a greater than $3 \log 10$-fold decrease in colony forming units, representing a $99.94 \%$ killing of bacteria, $p=0.0006845$ (Figure 1B). Efficiency of killing reached $99.99 \%$ after 1 minute $(p=0.0006824)$ and no CFUs were recovered after a treatment of 2 minutes $(p=0.00068204)$. We also tested the ability of the device to sanitize donated soiled cloth or surgical face masks that had been exposed to environmental microorganisms after being worn for a full day. We found that a variety of microbial colonies grew from swabs of worn masks from different individuals, including large colonies characteristic of Bacillus species (Figure 2A). Swabs were also taken from the internal face-side of each mask prior to UVC exposure or following 5 minutes of treatment measured at $0.8 \mathrm{~mW} / \mathrm{cm}^{2}$ at a distance of $10 \mathrm{~cm}$ from the light source. Samples were then streaked on LB plates and incubated for 24 hours. The results demonstrated that numerous microbial colonies grew from swabs of both the worn cloth and surgical masks and that no CFUs were recovered following UVC treatment of the same masks (Figure 2b). Finally, we tested the ability of the UVC device to sanitize the touch screen of a mobile phone, which is another possible source of transmissible microorganisms. A swab taken from the phone and transferred to an LB plate led to the growth of a number of microbial CFUs within 24 hours, albeit fewer than observed from facemasks (Figure 2C, upper panel). Swabs of the phone following treatment with UVC light for 5 minutes, as above, revealed that no CFUs emerged (Figure 2C, lower panel). 


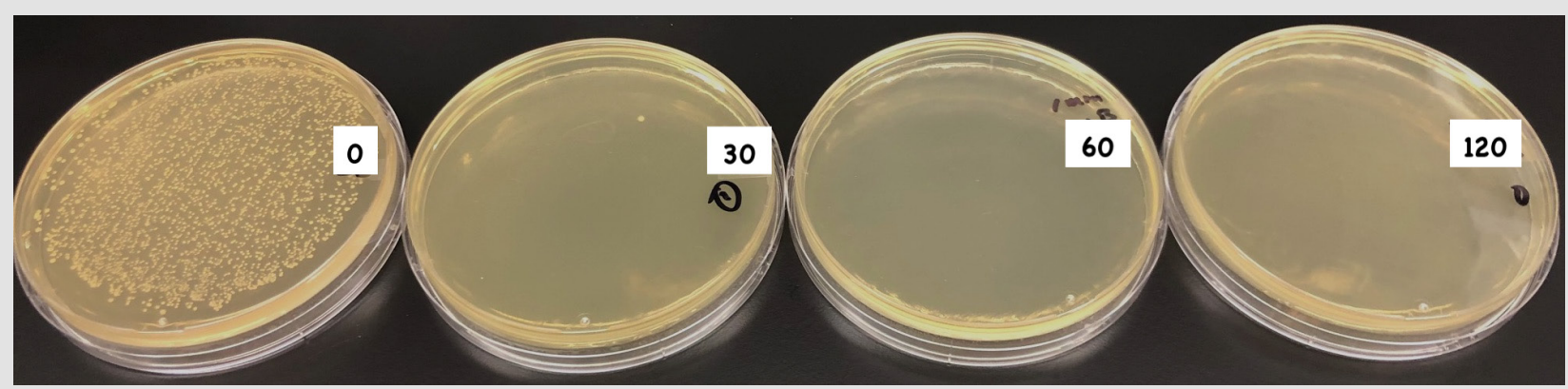

A

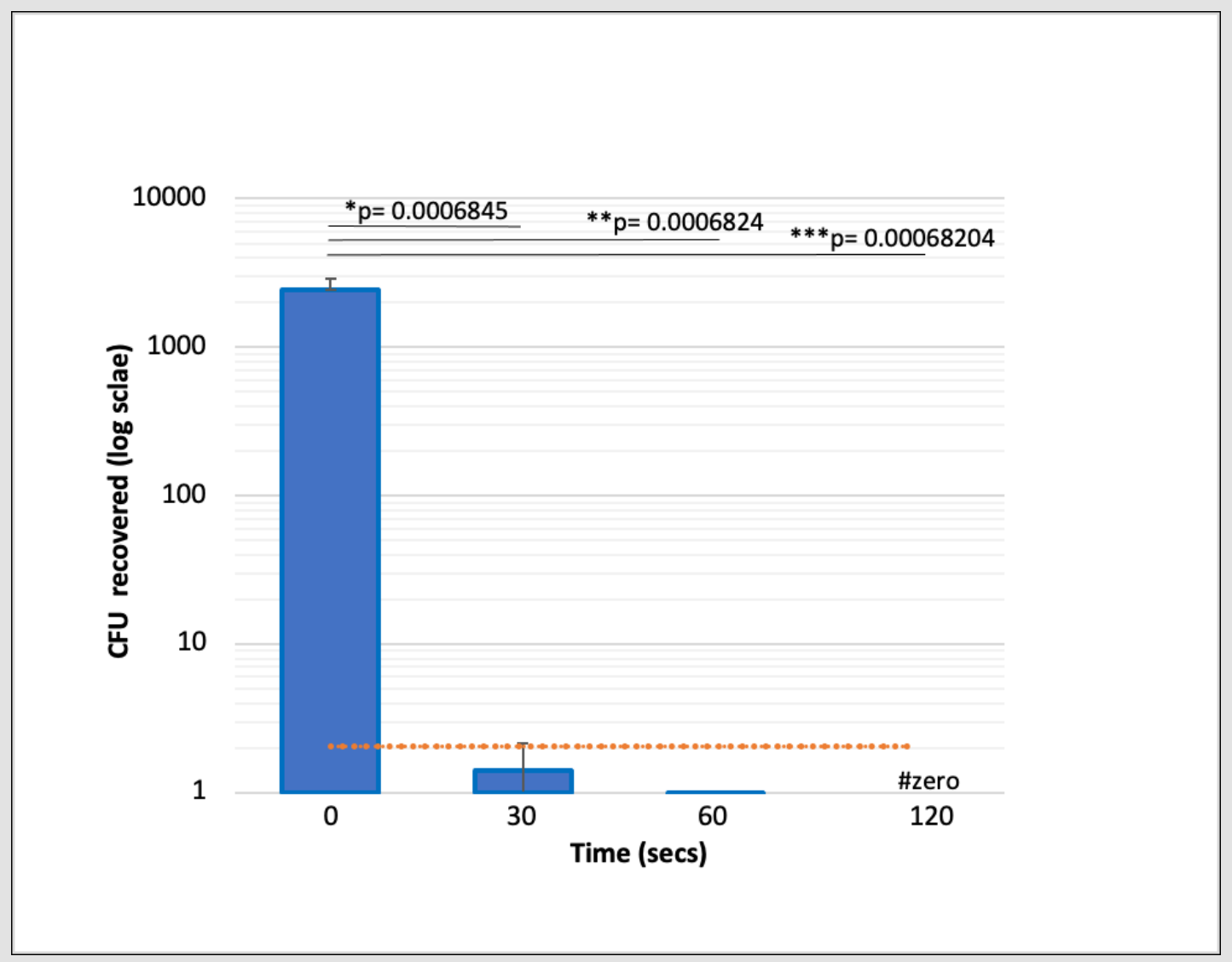

B

Figure 1: E.coli colonies recovered from surgical face masks following exposure to UVC light. Droplets of E.coli were spotted onto the inside surface of surgical facemasks and then recovered and grown on LB plates following exposure to UVC light for 30,60 or 120 seconds relative to control ( 0 seconds).

a) Representative plates of E.coli CFUs recovered from untreated masks or masks exposed to UVC light for 30, 60 or 120 seconds.

b) Shown are mean bacterial CFUs plotted on a log scale over time. Black horizontal lines represent the two-tailed p-values calculated from pairwise t-tests between 0 and $30 \mathrm{sec}$ exposure $\left(^{*}\right), 0$ and $60 \mathrm{sec}$ exposure $\left(^{* *}\right)$ and 0 and 120 sec exposure $(* * *)$. Vertical bars represent standard errors for each sample set. The orange line represents the hypothetical 3 log10 -fold decrease in CFUs to achieve $99.9 \%$ sanitization. Note that zero CFUs were recovered after 2 minutes exposure to UVC light (\#). 


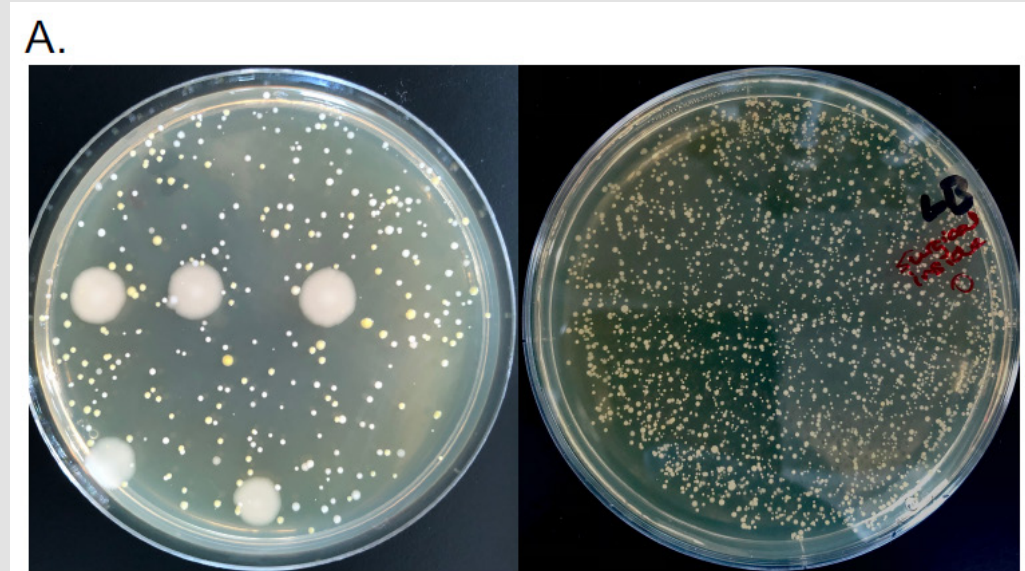

C.

B.

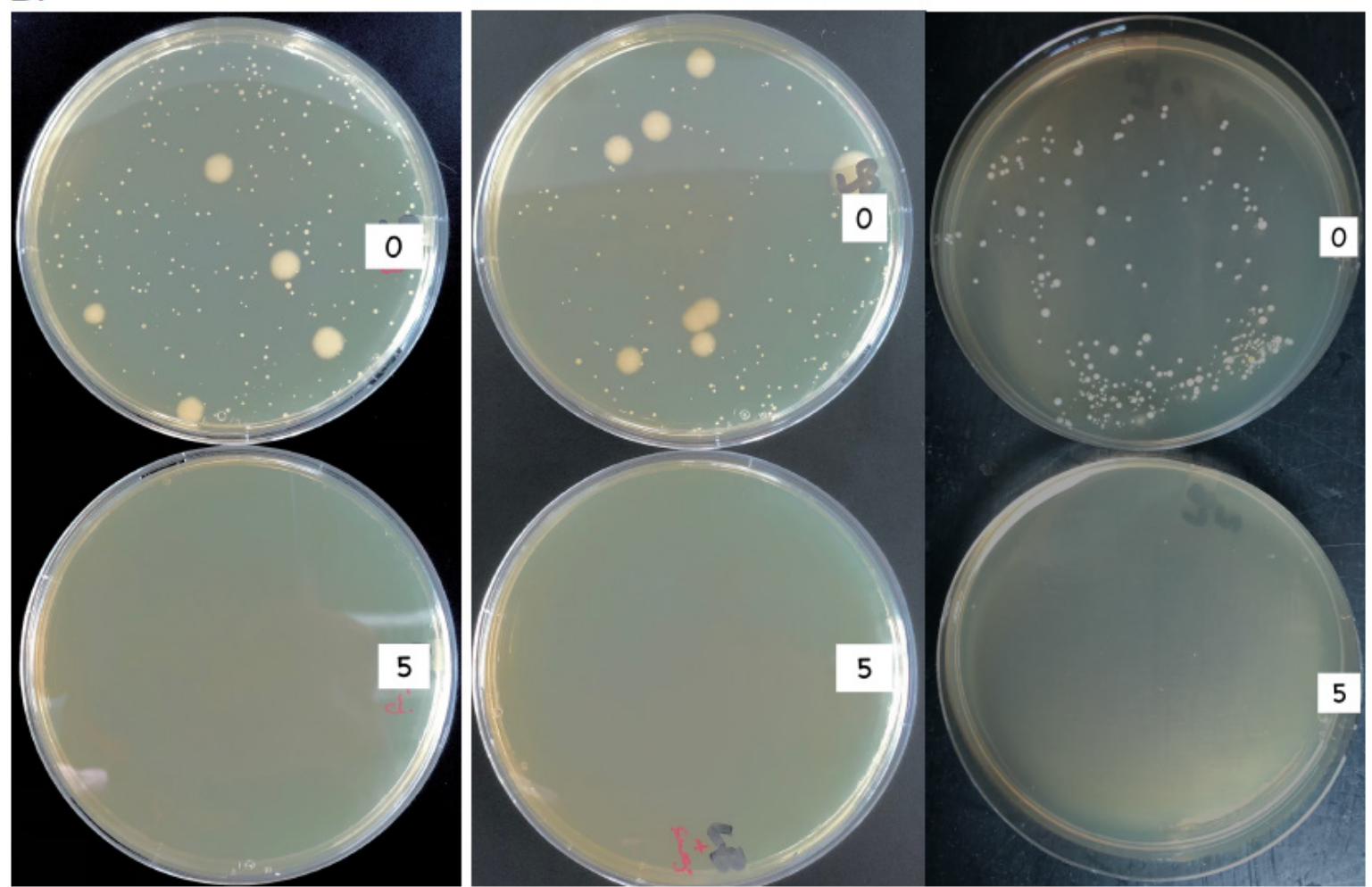

Figure 2:

a) Representative plates of microorganisms recovered from soiled untreated masks or masks exposed to UVC light. Microbial colonies grown from swabs of worn surgical face masks from two individuals.

b) CFUs recovered from surgical (left) or cloth (center) facemasks from individual A or from a surgical facemask from individual B (right). Swabs were taken from the inside surface of the facemasks following exposure to UVC light for 5 minutes (5) relative to untreated controls (0) and streaked on LB plates.

c) CFUs recovered from the touchscreen of a mobile phone. Swab taken from the glass surface of the phone following exposure to UVC light for 5 minutes (5; lower panel) relative to untreated controls ( 0 ; upper panel) and streaked on LB plates.

\section{Discussion}

UVC light with a wavelength of $254 \mathrm{~nm}$ is known to be an effective biocide. This radiation is capable of damaging nucleic acids thereby inhibiting the growth and deactivating the potential pathogenic qualities of microorganisms [17,24]. Importantly, the small portable prototype device we developed protects the user from excessive exposure to UVC light, which can cause eye or skin damage $[25,26]$. We found that it can be an effective way to sanitize face masks or other personal items to allow to their reuse. Our results also suggest that after each wear, bacteria from even a healthy wearer's own respiratory droplets and skin can collect on the inside of the mask and the outside of a mask may potentially contain pathogens capable of living on its surface, consistent with 
previous observations [27]. Although viability of viruses including SARS- CoV-2 were not monitored in this study, we demonstrated that treatment using the UVC device effectively eliminates bacterial/microbial growth within 2-5 minutes. Quantitative fit tests have shown that the filtration performance of $\mathrm{N} 95$ respirators was not markedly reduced after UVC decontamination and masks can retain comparable filtration performance to the control group after 2 rounds of decontamination and maintained acceptable performance after 3 rounds [22]. Therefore UVC can be an effective way to sanitize masks when supplies are low, allowing for their limited reuse and to reduce the environmental impact of disposal of non-washable face coverings.

\section{Acknowledgement}

Funding for these studies was provided by the Charles E. Schmidt College of Medicine of Florida Atlantic University. We are grateful for the guidance of Dana J. Vouglitois, JD, CLP and the Office of Technology Development at Florida Atlantic University. The device described in this study is subject to a provisional patent application [23].

\section{References}

1. Zhou L, Ayeh SK, Chidambaram V, Karakousis, PC (2021) Modes of transmission of SARS- CoV-2 and evidence for preventive behavioral interventions. BMC Infect Dis 21(1): 496.

2. Zhang R, Li Y, Zhang AL, Wang Y, Molina MJ (2020) Identifying airborne transmission as the dominant route for the spread of COVID-19. Proc Natl Acad Sci 117(26): 14857-14863.

3. Leung NHL, Chu DKW, Shiu EYC, Chan KH, McDevitt JJ, et al. (2020) Respiratory virus shedding in exhaled breath and efficacy of face masks. Nat Med 26(5): 676-680.

4. (2020) US Centers for Disease Control and Prevention. Recommendation Regarding the Use of Cloth Face Coverings, Especially in Areas of Significant Community-Based Transmission.

5. (2020) World Health Organization (WHO). Advice on the Use of Masks in the Context of COVID-19.

6. Brooks JT, Butler JC, Redfield RR (2020) Universal masking to prevent SARS-CoV-2 transmission the time is now. JAMA 324(7): 635-637.

7. Peeples L (2020) Face masks: what the data say. Nature 586(7828): 186189.

8. Prata JC, Silva AL, Walker TR, Duarte AC, Rocha Santos T (2020) COVID-19 pandemic repercussions on the use and management of plastics. Environ Sci Technol 54(13): 7760-7765.

9. Xu EG, Ren, ZJ (2021) Preventing masks from becoming the next plastic problem. Front Environ Sci Eng 15(6): 125.

10. Editorial (2021) US CDC's unexpected change of stance on mask use. Lancet Microbe 2(6): e225.

11. Ranney ML, Griffeth V, Jha AK (2020) Critical Supply Shortages-the need for ventilators and personal protective equipment during the Covid-19 pandemic. N Engl J Med 382(18): e41.
12. Worby CJ, Chang HH (2020) Face mask use in the general population and optimal resource allocation during the COVID-19 pandemic. Nat Commun 11(1): 4049.

13. Hamzavi IH, Lyons AB, Kohli I, Narla S, Parks Miller A, et al. (2020) Ultraviolet germicidal irradiation: Possible method for respirator disinfection to facilitate reuse during the COVID-19 pandemic. J Am Acad Dermatol 82(6): 1511-1512.

14. Lyons AB, Narla S, Torres AE, Parks Miller A, Kohli I (2021) Skin and eye protection against ultraviolet $\mathrm{C}$ from ultraviolet germicidal irradiation devices during the COVID-19 pandemic. Int J Dermatol 60(4): 391-393.

15. Bedell K, Buchaklian AH, Perlman S (2016) Efficacy of an automated multiple emitter whole-room Ultraviolet-C disinfection system against coronaviruses MHV and MERS-CoV. Infect Control Hosp Epidemiol 37(5): 598-599.

16. Beggs CB, Avital EJ (2020) Upper-room ultraviolet air disinfection might help to reduce COVID-19 transmission in buildings: A feasibility study. PeerJ 8: e10196.

17. Reed NG (2010) The history of ultraviolet germicidal irradiation for air disinfection. Public Health Rep 125(1):15-27.

18. Sabino CP, Sellera FP, Sales Medina DF, Machado RRG, Durigon EL (2020) UV-C (254 nm) lethal doses for SARS-CoV-2. Photodiagn Photodyn Ther 32: 101995 .

19. Inagaki H, Saito A, Sugiyama H, Okabayashi T, Fujimoto S (2020) Rapid inactivation of SARS-CoV-2 with Deep-UV LED irradiation. Emerg Microbes Infect 9(1): 1744-1747.

20. Heilingloh CS, Aufderhorst UW, Schipper L, Dittmer U, Witzke O, et al. (2020) Susceptibility of SARS-CoV-2 to UV irradiation. Am J Infect Control 48(10): 1273-1275.

21. Ozog DM, Sexton JZ, Narla S, Pretto Kernahan CD, Mirabelli C, et al. (2020) The effect of ultraviolet $C$ radiation against different N95 respirators inoculated with SARS-CoV-2. Int J Infect Dis 100: 224-229.

22. Fischer RJ, Morris DH, Van Doremalen N, Sarchette S, Matson MJ, et al. (2020) Effectiveness of N95 respirator decontamination and reuse against SARS-CoV-2 Virus. Emerg Infect Dis 26(9): 2253-2255.

23. Grant PA (2020) Apparatus and method for UV-C sanitization of contaminated masks in a household or workplace environment. Provisional Patent Application F1193/2003.

24. Casini B, Tuvo B, Cristina ML, Spagnolo AM, Totaro M (2019) Evaluation of an Ultraviolet C (UVC) Light-Emitting Device for Disinfecton of High Touch Surfaces in Hospital Critical Areas. Int J Environ Res Public Health 16(19): 3572.

25. Zaffina S, Camisa V, Lembo M, Vinci MR, Tucci MG, et al. (2012) Accidental exposure to UV radiation produced by germicidal lamp: case report and risk assessment. Photochem Photobiol 88(4): 1001-1004.

26. Trevisan A, Piovesan S, Leonardi A, Bertocco M, Nicolosi P, et al. (2006) Unusual high exposure to ultraviolet-C radiation. Photochem Photobiol 82(4): 1077.

27. Brosseau LM, McCullough NV, Vesley D (1997) Bacterial Survival on Respirator Filters and Surgical Masks. Journal of the American Biological Safety Association 2(3): 32-43. 


\section{ISSN: 2574-1241}

DOI: 10.26717/BJSTR.2021.36.005908

Patrick A Grant. Biomed J Sci \& Tech Res

(C) (P) This work is licensed under Creative

Submission Link: https://biomedres.us/submit-manuscript.php

$\begin{array}{ll}\text { BIOMEDICAL } & \text { Assets of Publishing with us } \\ \text { RESEARCHES } & \text { Global archiving of articles } \\ & \text { - Immediate, unrestricted online access }\end{array}$

